\title{
OCLC's Database Conversion: A User's Perspective
}

Arnold WAJENBERG and Michael GORMAN: University of Illinois Library, Urbana-Champaign

This article describes the experience of a large academic library with headings in the OCLC database that have been converted to AACR2 form. It also considers the use of LC authority records in the database. Specific problems are discussed, including some resulting from LC practices. Nevertheless, the presence of the authority records, and especially the conversion of about 40 percent of the headings in the bibliographic file, has been of great benefit to the library, significantly speeding up the cataloging operation. An appendix contains guidelines for the cataloging staff of the University of Illinois, Urbana-Champaign in the interpretation and use of $L C$ authority records and converted headings.

The library of the University of Illinois, Urbana-Champaign, is the largest library of a publicly supported academic institution, and the fifth largest library of any kind, in the United States. In the last year for which figures are available (1979-80), the library added more than 180,000 volumes representing more than 80,000 titles. The library is currently cataloging more than 8,000 titles a month; more than 80 percent of the records for these titles are derived from the OCLC database (Library of Congress and OCLC member copy).

Because our cataloging is of such volume and because we are actively engaged in the development of an online catalog, we decided to use the second edition of the Anglo-American Cataloguing Rules (AACR2) earlier than the "official" starting date of January 1981. We began to use AACR2 for all our cataloging in November 1979. This early use of AACR2 has led to two consequences. First, we now have OCLC archival tapes representing about 150,000 titles cataloged according to AACR2. This represents a valuable and continuously growing bibliographic resource that can be used without modification in our future online catalog. Second, we have a considerable and unique collective experience in the practical application of AACR2. The minor problems of working with AACR2 in an AACR1

Manuscript received June 1981; accepted June 1981. 
plus superimposition environment (until January 1981) were more than compensated for by these two positive results.

\section{OCLC CONVERSION}

With our practical background in the use of AACR2 and our continuing need for a high volume of cataloging, we were, naturally, keenly interested in the (to our mind) progressive decision of OCLC to use machine matching techniques to convert the form of name and title headings in its database - the Online Union Catalog (OLUC) - to conform to AACR2. We recognized the limitations of the project, essentially those defined by the capabilities of the computer for matching character by character, but felt that this was a major venture that would, when completed, produce major benefits.

What follows is an assessment and analysis of the results of the project in the light of the experience of a library that is dedicated to achieving highvolume, quality cataloging. We deal with the LC authority file as well as the OCLC headings because the LC file was the basis of the project and because, from the practical point of view, the two files are complementary aspects of the same service.

The greatest value of the conversion, and its greatest claim to uniqueness, lies in the sheer size of the project in terms of headings checked and changed. Our catalogers, and others who work with current materials, estimate that more than 40 percent of the name and title fields we use in our current cataloging have a $w$ subfield indicating that the name or title has been changed to its AACR2 form. Since OCLC estimates that 39 percent of the name and title fields were affected by the conversion, it would appear that the headings that were changed are the headings that we are more likely to use. In other words, the project has brought us more than a 39 percent benefit. We are also greatly encouraged to find that the number of headings coded $d n$ (meaning AACR2 "compatible," or, more bluntly, LC's modifications of the provisions of AACR2) is a very tiny minority of all converted headings. This means that when, in the future, this policy of "compatibility" is lessened or dropped, there will be relatively few changes to be made.

\section{LC AUTHORITY RECORDS}

We also benefit from the presence of LC authority records in the OCLC database when we establish headings that are new to our catalogs. There is one problem with the use of these records, which was revealed by a sample of new University of Illinois authority records (see table 1). This sample of 368 new University of Illinois records reveals that LC authority records are available relatively rarely for new headings. This is not surprising as these new headings are established most often as part of the process of original cataloging, which, almost without exception, occurs in our library only when OCLC copy is not available. It seems to us to be unfortunate that 
Table 1. Recently Established Headings

\begin{tabular}{|c|c|c|c|c|}
\hline & $\begin{array}{c}\text { No } \\
\text { Authority } \\
\text { Record }\end{array}$ & $\begin{array}{c}\text { Record } \\
\text { Coded } \\
c^{*}\end{array}$ & $\begin{array}{c}\text { Record } \\
\text { Coded } \\
d^{*}\end{array}$ & $\begin{array}{c}\text { Record } \\
\text { Coded } \\
n^{*}\end{array}$ \\
\hline Given name headings & 13 & 5 & 0 & 1 \\
\hline $\begin{array}{l}\text { Single surname headings } \\
\text { (Number of this }\end{array}$ & 212 & 26 & 2 & 2 \\
\hline $\begin{array}{l}\text { category with } \\
\text { initialisms ex- } \\
\text { panded in parentheses) }\end{array}$ & (132) & (7) & (1) & (2) \\
\hline $\begin{array}{l}\text { Compound surname headings } \\
\text { (Number of this }\end{array}$ & 29 & 12 & 0 & 1 \\
\hline $\begin{array}{l}\text { category with } \\
\text { initialisms ex- } \\
\text { panded in parentheses) }\end{array}$ & (2) & $(0)$ & (0) & $(0)$ \\
\hline $\begin{array}{l}\text { Single surnames plus } \\
\text { uniform titles }\end{array}$ & 3 & 0 & 0 & 0 \\
\hline $\begin{array}{l}\text { General corporate } \\
\text { headings }\end{array}$ & 34 & 12 & 0 & 0 \\
\hline $\begin{array}{l}\text { General headings with } \\
\text { subdivisions }\end{array}$ & 7 & 2 & 0 & 0 \\
\hline Government headings & 4 & 2 & 0 & 1 \\
\hline Total & 302 & 59 & 2 & 5 \\
\hline \multicolumn{5}{|c|}{$\begin{array}{l}\text { "Key: } \\
\text { c-in subfield } w \text {, indicates an AACR2 form, as established by Library of Congress. } \\
\text { d-in subfield } w \text {, indicates an AACR2 "compatible" form, as established by Library of Congress. } \\
\mathrm{n} \text {-in subfield } w \text {, indicates that the input operator could not determine which set of rules } \\
\quad \text { governed the form of the heading. }\end{array}$} \\
\hline
\end{tabular}

member libraries cannot contribute their authority records to the OCLC database. Our experience suggests that the online authority file would grow very rapidly if that were the case. To put it another way, the OCLC conversion provides an enormous and valuable resource of AACR2 headings. It did not, and could not, provide new authority information. OCLC will be complementing its valuable work in upgrading the retrospective file when it devises and implements a scheme for making available authority records for new headings derived from a wide range of sources. Since so many headings were converted to AACR2, it may seem churlish and ungrateful to complain that more was not done. The following descriptions are not intended to form part of an attack on OCLC's project or to minimize its achievement.

\section{FORM SUBDIVISIONS}

The project failed to delete form subdivisions (such as "Liturgy and ritual" and "Laws, statutes, etc.") from added entry headings and subjects. The program correctly deleted them from main entry headings, but the inconsistencies resulting from their retention elsewhere makes the job of ensuring consistency in a large copy cataloging operation that much harder. 
This inconsistency in treatment is illustrated by examples 1 and 2 .

Example 1 originally was entered under

11010 Illinois. k Laws, statutes, etc.

The program correctly changed the main entry heading to

11010 Illinois

and added a subfield $w$, coded $m n$ (the $m$ indicates a conversion by machine to the AACR 2 form; the $n$ means "not applicable," and indicates that there is no title element in the heading).

Example 2 has as main entry

\section{Illinois Community College Board}

but has as added entry

71010 Illinois. k Laws, statutes, etc. t Illinois

public community college act

Under AACR2, the subfield $k$, "Laws, statutes, etc.," should not be present in the heading. Unfortunately, the program looked only at 110 fields, not at 710 fields, and so the heading was not corrected in the conversion. It must therefore be edited manually by every library that uses the record.

\section{PROGRAM PROBLEMS}

Our direct use of the online authority file is somewhat hampered by the programming oversight that makes it impossible to search uniform titles. Of course, uniform titles that are accompanied by a 100 field (notably in music) can be retrieved by an author search, but those without 100 fields (anonymous classics, sacred scriptures, etc.) are virtually inaccessible.

There were a handful of specific instances in which the specifications were inadequate or the programs seem to have malfunctioned. These resulted in some oddities such as the conversion of the subject "Jesus Christ" to "Sermon on the Mount" and the (surely not politically motivated) switch from "U.S. Department of State" to "Voice of America." OCLC has been scrupulous in identifying and publicizing these errors. They are few in number and, though conspicuous, have rarely caused us many problems.

As can be seen, the problems caused by what we see as failures on OCLC's part are few and affect few cataloging circumstances. The remaining problems either result from the decisions and actions of the Library of Congress and, hence, are wholly or mostly out of OCLC's control, or are of such a nature that they cannot be solved by computer matching techniques without extensive editorial intervention. Whether such human intervention is possible and, if possible, cost-beneficial is not for us to say, though it must be recognized that to transform the OLUC to pure AACR2 conformity would be a herculean task. That task would undoubtedly involve many of the hundreds of thousands of records that are seldom or never used. 
Sicrest 1 of 2

UIII - FOF DTHEF HOLIINIS, ENTEF dH DEFFESE IISFLAY FEDD SEND

OLLI: 7044265 Fer stat: - Entrd: 510102 Used:

Trpe: a Eit Iv1: m Govt fub: 5 Larig: eng Source: d Illus:

Fepr: Eric TVi: I Corif pub: O Ctry: ilu liat tp: $5 \mathrm{M} / \mathrm{F} / \mathrm{E}: 10$

Iride: O Mad rec: Festschr: O Lont:

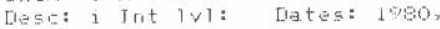

$\begin{array}{lll}1 & 010 \\ 2 & 040 & 0401\end{array}$

$30 \% 2 \quad 346.045$ b I2\% , 1980

$4092 \quad b$

5049 UIUU

A 11010 I11inois. w mir

724510 I1 1 inois laus relatira to flanring and development / c prepared

br [ivisian of Government ard Eammuntr Services, Dffice of Hausing and Communitr Development.

82609 [Sfringfie1d] : ti State of I11inois, [rept. of Commerce and Communitr Affairs, 1980.

9265 Illinois Dept. of Commerce o commoitr Affairs, 222 50.501109 St., Springfield, IL. 62706 .

$10300 \quad 89$ F. ; c 28 .

11. 4901 Fieferenca saries - Department of Commerce arid Commuritr Affairs; 1980

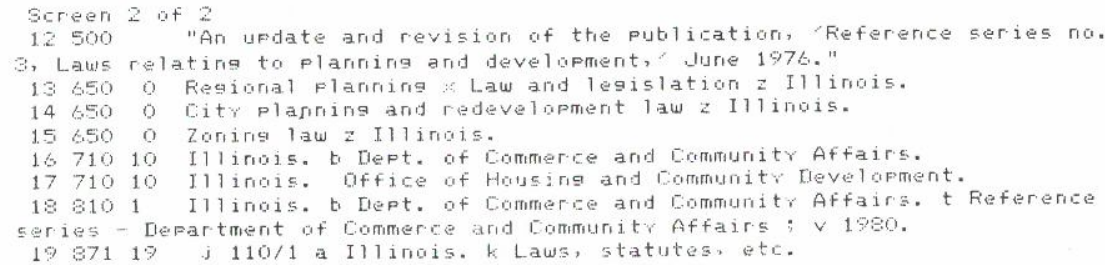

\section{Example 1}

Eicreen 1 of 2

WIU - FDR DTHEF HDLIINGS, ENTEF dh DEFRESS IIISFLAY FECD SENL

OLLC: $b 606254$ Fec stat: n Entrd: 800811 Used: 810325

Trpe: a Bjt |vi: m Govt pub: s Lang: eng Source: d Illus:

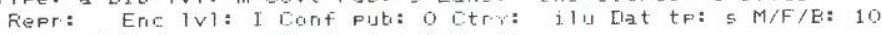

Indx: o Mad rec: Festsitir: 0 Cont:

Desc: i Int Iv1: [lates: 1979 .

1010
2040 $\quad$ SFI S SFI d $m_{i} \mathrm{c}$

$3043 \quad$ n-us-il

$4092 \quad 344.074$ b. I29Le

$5092 \quad b$

6049 UIIII

711020 Illinois Communitr Lollege Board w Er

824510 Legislatian enacted into lau fram the 1978 and 1979 sessions of

the Illinois General Assembly that affect the Ilinois public communitr college srstemi.

92600 Springfield: $b$ Illinois Communitr Dollege Board, $c 1979$.

10263 Il inois Commritr College Board, 3ogs Stevenson Dr. Sprirgfield.

I11. 62703

$11300 \quad 44,[21]$ P. ; c 28: cm.

12500 Cover titie.

Sicrean 2 of 2

13500 Appendix includes supplements to the Illinois public cammunitr

college act.

14650 O Communtr colleges $\times$ Law arid legislation z Illinois.

1571010 Illinois. k Laws, statutes, etc. t Illinois putic communitr college act. 


\section{SERIALS}

The most troublesome example of the kind of problem that cannot be resolved by machine matching is that of serials. The OCLC conversion project was, quite properly, not concerned with choice of entry (AACR2, chapter 21). This seems a simple and clearly defined decision. When we come to consider serials, this clear distinction between choice and form of entry becomes blurred. The major change brought about by AACR2 (rule 21.1B2) is that many serials previously entered under the heading for a corporate body are to be entered under their titles. In fact, the great majority of serials will now be entered under title. The upshot of this is that the citation (or form of heading) for a serial changes from, for example,

\section{National Society for Medical Research. Bulletin}

to

\section{Bulletin / National Society for Medical Research}

The restriction of the OCLC project to forms of heading means that most serials in OLUC will be found under headings the form of which may be correct but are inappropriate for citations. This problem, which, of course, cannot be resolved by computer matching, has led to difficulties for us in copy cataloging, because a degree of expertise is needed to apply AACR2 rule $21.1 \mathrm{~B} 2$ and to distinguish between the majority of serials where the 110 field should be changed to a 710 and the small minority where the 110 field should remain as it is. Since most serials are to be entered under their titles, it occurs to us to suggest that the OCLC conversion project could have changed all 110 fields in records identified as relating to serials to 710 . By that method, the majority of serials would be correctly entered and the potential for mistaken citations greatly reduced.

\section{MULTIPLE PERSONAL NAMES}

Persons who write under more than one name (real names, pseudonyms, etc.) and who are not primarily identified by one of those names (AACR2 22.2C3) pose a special problem. Under the provisions of AACR2, such persons are to be represented in the catalog (and the database) under two or more names. Despite the fact that "Creasey, John" and "Marric, J. J." and "Ashe, Gordon" are all names used by the same man, they will appear as separate headings from now on. Under AACR1 plus superimposition one of those names ("Creasey, John") was used as the heading for all works. Within the confines of the OCLC project, there was no method available to distribute the various records under the various headings. It occurs to us that some method based on matching the name found in the $245 \$ \mathrm{c}$ subfield with the 100 field might, at least, have resulted in the project recognizing probable cases calling for multiple headings. For example:

100 a Hibbert, Eleanor

245 a Bride of Satan / \$c Jean Plaidy 
could alert the system to a case for change. We recognize that this would call for more sophisticated computer matching techniques and that it would call for editorial intervention. A good example of the problem this has caused for us is the case of the Danish author Karen Blixen. She wrote under that name and under the pseudonyms Isak Dinesen and Pierre Andrézel. Records in the database that were added before 1981 will use "Blixen, Karen, 1885-1962" as the heading for all her works including those published under pseudonyms. Since the Blixen heading is a perfectly acceptable AACR2 form, the conversion program codes it as an AACR2 heading, which it is for the Blixen books but is not for those published under other names.

The authority record (example 3 ) includes a note identifying both pseudonyms as valid AACR2 headings, but, of course, the programs as written cannot interpret such a note and match them with appropriate records.

\section{CORPORATE NAME CHANGES}

Corporate bodies present a similar problem when one is dealing with those that have changed their name. Until 1967, the Library of Congress used the latest name of such bodies with see references from the earlier names. Both editions of $A A C R$ require that works issued under the earlier names be entered under those names and works issued under the latest name be entered under that name, the various names being connected by see also references. However, records in the OLUC for earlier works cataloged before 1967 will show those works entered under a later name.
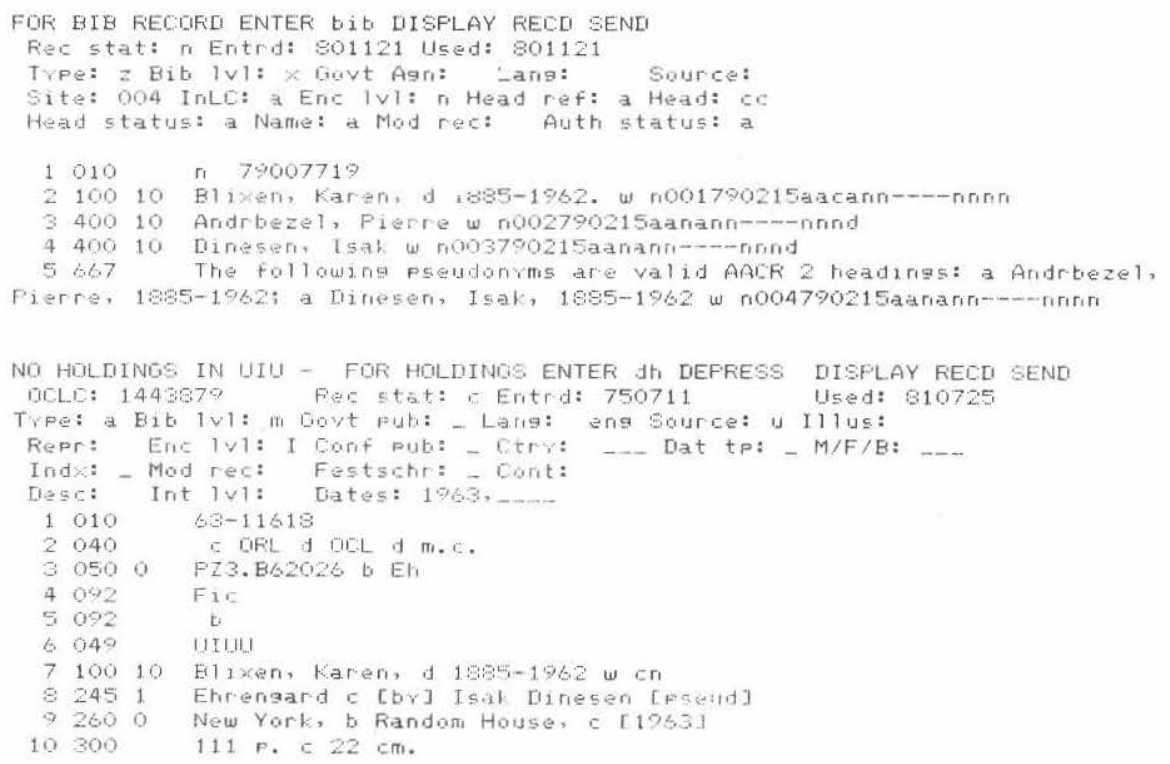

Example 3 
Because those later names are valid AACR2 headings in terms of their form, they are coded $c n$ (i.e., AACR2 validated) by the program, even though they may not be the right headings for the records to which they are attached. A good example of this problem is that of the "Lutheran ChurchMissouri Synod." An earlier name of this religious body is "Deutsche Evangelisch-Lutherische Synode von Missouri, Ohio, und Andern Staaten." Unfortunately, the authority record (example 4) does not even show that the earlier name is valid according to AACR2. The conversion program, on encountering the earlier name used as a heading, would change it to the later name and code that form as being the AACR2 heading.

Another example of the problem is:

Chamber of Commerce of the United States of America. International Department

This is identified as the AACR2 form (example 5) but, in fact, the department has changed its name to "International Division."

\section{LC PRACTICE}

Another problem we have encountered is that of the literal-mindedness of the computer programs in matching like with like. This problem is compounded by inconsistencies in cataloging practice resulting from variations in LC cataloging practice. An example of this problem is that of the Nigerian author Chinua Achebe. The heading "Achebe, Chinua" is marked as being AACR2 despite the fact that the authority record shows

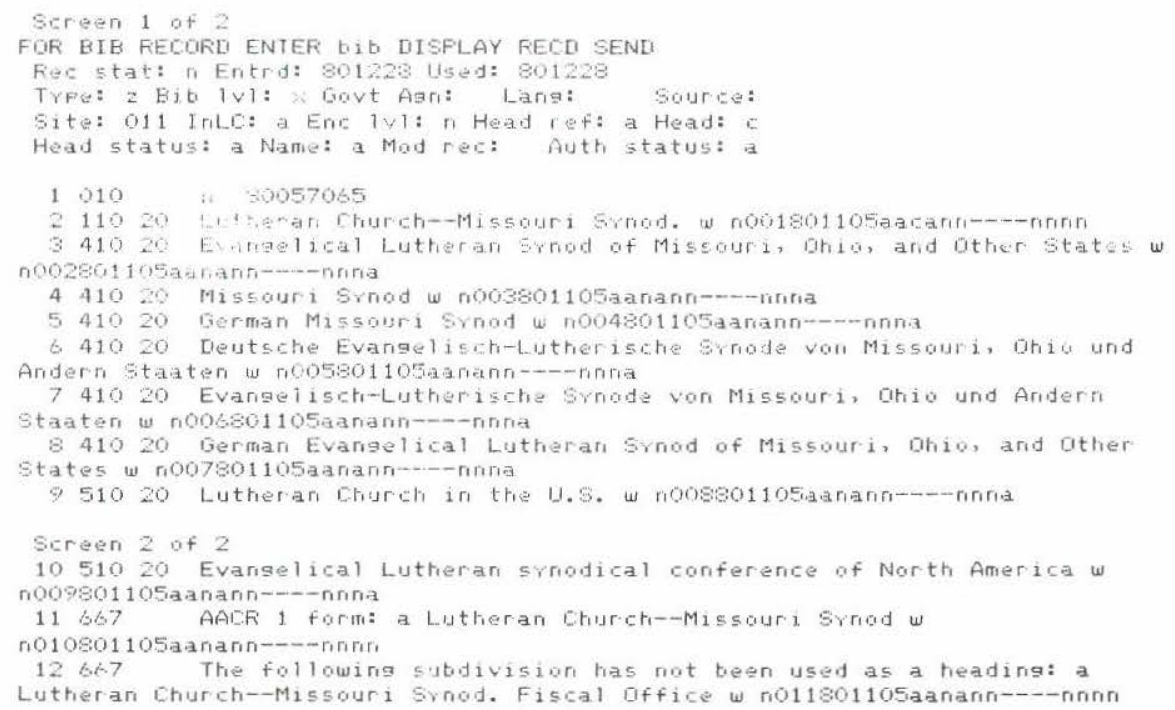




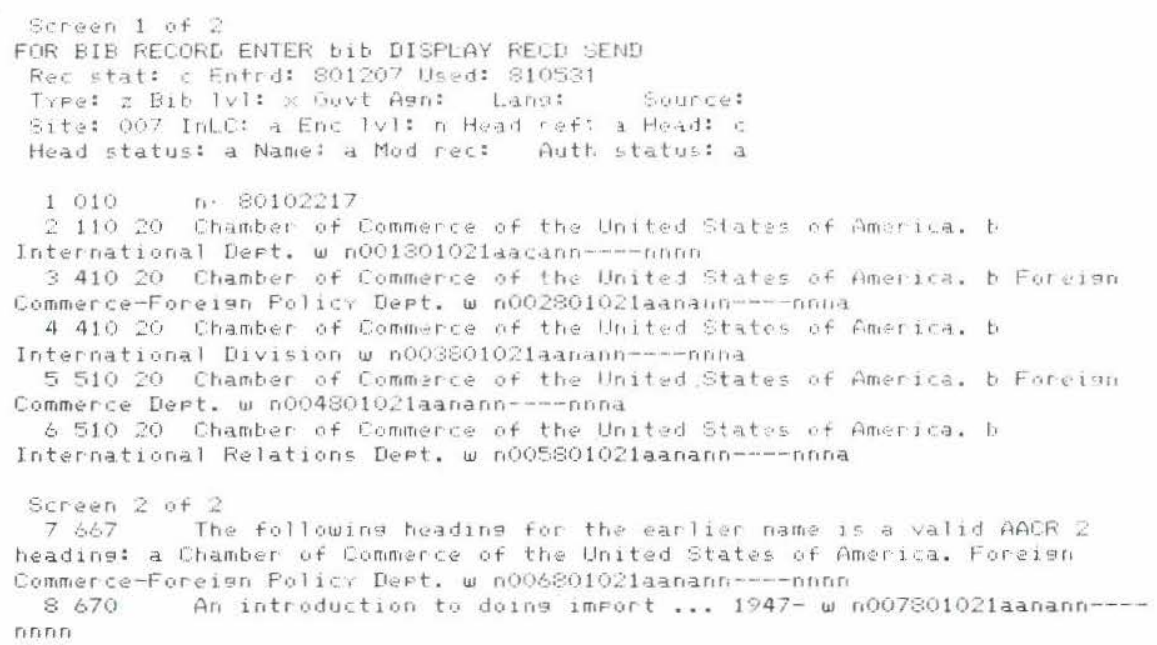

\section{Example 5}

that he was born in 1930. LC's announced policy is to give dates "whenever the information is readily available," but only for headings established after December 1980. This restriction creates inconsistencies in LC practice that are hard to predict. The result is that we often establish a personal heading with a date, only to discover that $\mathrm{LC}$ is not using it. The definition of "readily available" is clearly elastic and does not provide clear guidance to other libraries. It is irritating and occasionally burdensome but does not create a quantitatively serious problem.

One unfortunate result of LC's machine conversion of its authority file to AACR2 forms has been to make notes on the authority records harder to understand. This is because only headings and references were changed; notes were not affected. This means that the wording of the notes may refer to a state of affairs that has altered as a result of the AACR2 conversion.

Example 6 is the authority record for the AACR 2 form of heading for the University of Illinois prior to the change of name in 1966 . The history note (field 667) incorrectly says that the heading for works published before 1966 is "Illinois. University" (the pre-AACR2 form). Since the AACR2 form as established by LC looks very much like the new name, "University of Illinois at Urbana-Champaign," the authority card is very difficult to understand. Nothing short of revising the note, and/or the use by LC of a less confusing qualifier than "(Urbana-Champaign campus)," will make the authority record intelligible.

An example of how LC practice has affected the OCLC program adversely is in the area of the so-called compatible headings. These are instances of when LC has chosen to depart from the provisions of AACR2 for one reason or another. Leaving aside the utility and morality of such a policy, it presents a considerable problem to those of us who use OCLC 
records. The example that follows is of the worst of these "compatible" practices. LC has decided to ignore the common form of name for persons who are not "famous or published under an American imprint."1 Thus, the writer P. C. Boeren would be recorded as "Boeren, P. C. (Petrus Cornelis), 1909- " under the provisions of AACR2, but, because Boeren is neither famous nor American, the "compatible" heading will be "Boeren, Petrus Cornelis, 1909_ ." This heading is not acceptable in an AACR2 catalog.

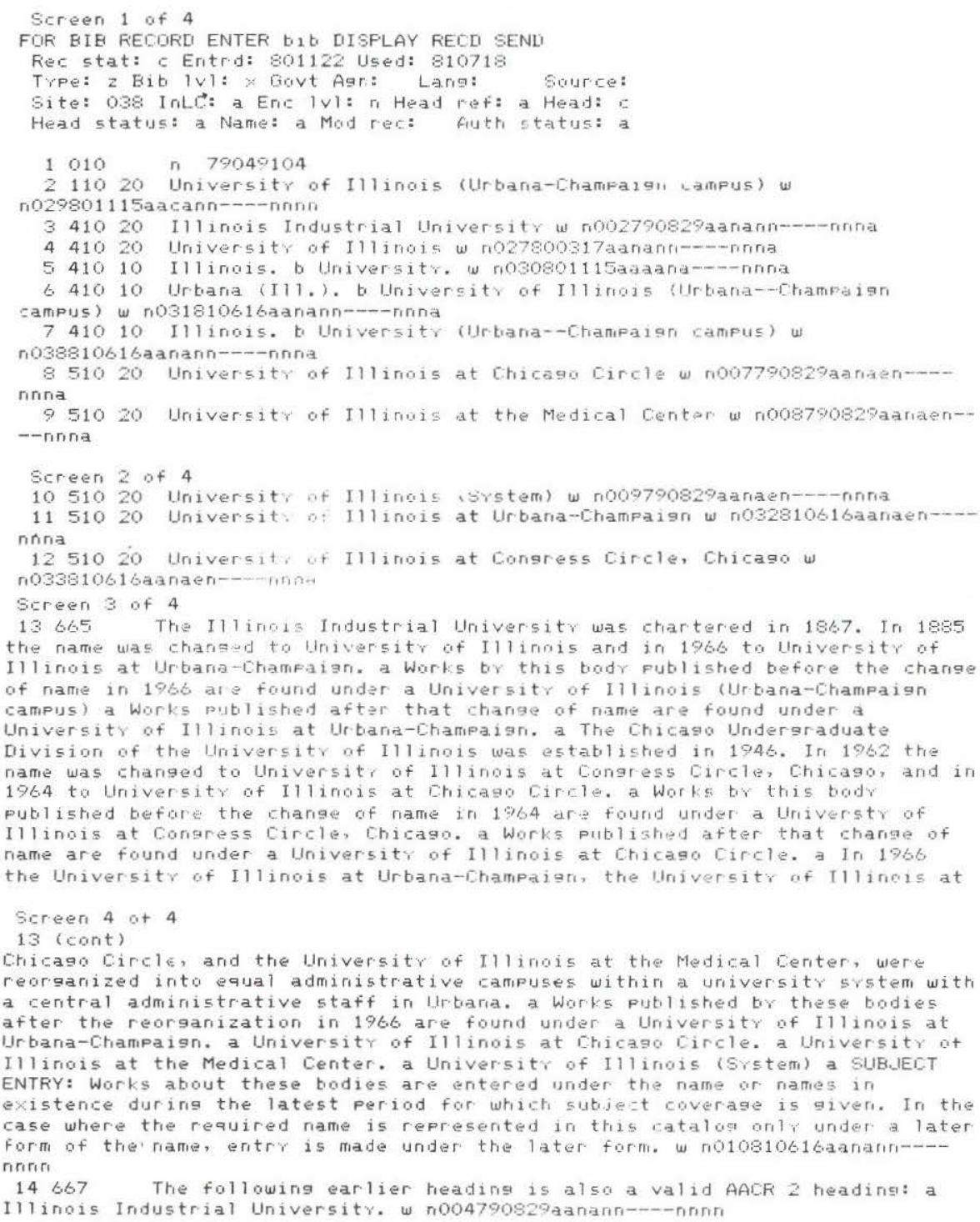


More, it is quite possible that if Boeren's works are published in America or if LC suddenly decides that Boeren is "famous," the heading will be changed. This is an infrequently encountered problem for us but one where LC's peculiar policies have created problems that have nothing to do with OCLC or AACR2.

\section{CONCLUSION}

The problems that we have cited above are real but not numerically significant (except in the case of serials and multiple personal namesneither of which are under OCLC's control). They are far outweighed by the tremendous value of the more than 40 percent of OCLC headings that have been converted to their AACR2 form.

The OCLC conversion has made it possible for us to do AACR2 cataloging more quickly than in the period November 1979-December 1980. We have issued guidelines to our professional, paraprofessional, and clerical cataloging staff who deal with all the headings we encounter in using OCLC (see appendix).

Problems such as those we have described are dealt with in our guidelines, and in practical terms now in day-to-day work. They may take some extra time, but overall our cataloging operation has been greatly speeded by OCLC's conversion.

\section{REFERENCE}

1. Cataloging Service Bulletin, no.6:6(Fall 1979)

\section{APPENDIX \\ University of Illinois Library at Urbana Champaign \\ Copy Cataloguing Guidelines}

Authority Records

LC authority records, now available on OCLC, can be very helpful in determining the correct AACR 2 form of headings, and should be cited on authority cards we prepare, when we use them in establishing headings.

The tag numbers used on authority records sometimes have different meanings from the numbers used on bibliographic records. The meanings are:

lxx Heading

$4 \mathrm{xx}$ See reference (i.e. from the form in this field to the form in the $1 \mathrm{xx}$ field)

$5 \mathrm{xx}$ See also reference (i.e. from the form in this field to the form in the $1 \mathrm{xx}$ field)

6xx Notes (e.g. the authority used by the LC cataloguer)

Each field concludes with a w subfield, consisting of 24 characters indicating in coded form various types of information about the heading. The 13th character, the 3rd past the six-character date, consists of one of five letters indicating the rules governing the form of heading in that field. The codes are: 


\author{
c AACR 2 \\ d Compatible with AACR 2 \\ b AACR, 1967 ed. \\ a Earlier rules (e.g., ALA rules of 1949, etc.) \\ n Not applicable or not applied
}

Here is an example of an LC authority record, omitting the fixed field and some of the references:

010 n 790558820

11020 State University of New York at Buffalo. w n008801115aacann----nnnn

41010 Buffalo. b University w n002791105aaaann----nnna

41010 New York (State). b State University, Buffalo. w n009801115aaaann----nnna

667 The following heading for an earlier name is a valid AACR 2 heading: University of Buffalo. w n007791105aanann----nnnn

When OCLC carried out its AACR 2 conversion project, the data about the rules encoded in subfield w was added to headings in bibliographic records, if those headings were altered by the conversion. For bibliographic records in OCLC, subfield w contains 2 characters, each of which must be one of the following:

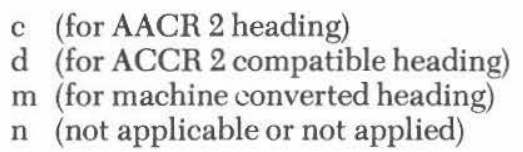

The first character applies to the name portion of the heading; the second, to the title portion. Obviously, in many cases there is no title portion, in which case the second character will be $\mathrm{n}$. The code $\mathrm{m}$ (machine converted heading) is used when a heading is altered directly by program, rather than being extracted from an authority record. An example would be the elimination of subfield $\mathrm{k}$ Laws, statutes, etc.

\title{
1. USE OF SUBFIELD W IN CATALOGUING
}

Since OCLC does not want member libraries to apply the letter codes in subfield $w$ for their original input, the presence of a $\mathrm{c}$ or $\mathrm{d}$ in subfield $\mathrm{w}$ should always indicate an LC decision identifying an AACR 2 or AACR 2 compatible heading.

Supply subfield $w$ for all cataloguing to be added to OCLC's data base. The codes to be used are given in ILLINET"s Information Bulletin \#92, from which this table is copied:

1 AACR 2 form found in on-line LC Name-Authority File

2 AACR 2 compatible form in on-line LC Name-Authority File

3 AACR 2 form supplied by inputting institution with copy in hand and piece not in hand

4 AACR 2 form supplied by inputting institution with piece in hand

5 Author or title portion of heading not converted to AACR 2 form.

This subfield (\#w) is always the last subfield in the field. It must contain a two character code. The first character applies to the name portion of the heading; the second character applies to the title portion of the heading. If the heading is a name heading and does not include a title portion, use " $n$ " as the second part of the code. If the heading is a uniform title heading, use " $n$ " as the first part of the code. Examples:

70010 Day Lewis, C. \#q (Cecil), \#d 1904-1972 \#w In

60010 Schmidt, H. R. \#q (Heinrich Rudolf) \#w 4n

13000 Bible. \#p N.T. \#s Authorized. \#f 1974. \#w n4

Accept headings coded $\mathrm{c}$ in subfield $\mathrm{w}$ as correct AACR 2 headings, unless the heading is for an author entered under surname who writes in a non-Roman alphabet language. For such 
authors, use the form given only if it is a standard romanization of the name in the original alphabet. If a form other than the standard romanization is used, substitute the standard romanization, and trace an $\mathrm{x}$ ref. from the form coded $\mathrm{c}$.

\section{LC AUTHOR HEADINGS WITHOUT DATES}

LC recently announced that it will not add dates to a heading already established without dates, unless the dates are needed to resolve a conflict. When there is no conflict, the dates will be recorded in the authority record in a $6 \mathrm{xx}$ field, but will not be added to the heading. Dates will be routinely added to newly established headings at the time the headings are established, if the information is readily available. LC codes such headings c, not d, because AACR 2 does not require that a date be added to the heading, except to resolve a conflict. If such an LC authority record is available when a heading is being established, use the LC form, without adding dates to the heading, unless dates are needed to resolve a conflict in the new catalogue. Record the dates on an authority card. If LC authority is not available when a heading is being established, use dates in the heading if the information is readily available. If, later, LC authority is found that omits date from the heading, do NOT change the heading as already established for the UIUC new catalogue. Since records in OCLC may contain headings without dates for persons we have established with dates, some conflicts will be generated. These should be resolved by catalogue maintenance staff, who will add dates in pencil to headings on new cards that lack dates, but are otherwise identical with headings in the new catalogue. Such conflicts in the machine record will be cleaned up gradually, after FBR is up.

\section{ACCEPTABLE dn FORMS}

Headings coded $\mathrm{d}$ in authority records ( $\mathrm{dn}$ in bibliographic records) are the AACR 2 "compatible" forms. In many cases, the difference from AACR 2 is trivial, and the form can therefore be used. In such cases, if LC authority is available, use the form as established by LC, and record the information on an authority card. If LC authority is not available when a heading is being established, follow AACR 2. If, later, LC authority is found that establishes a "compatible" form, do NOT change the form in the UIUC new catalogue to the LC "compatible" form. It will sometimes happen that "compatible" forms will be found on records in OCLC (coded dn, usually). Such headings may be used only if they fall into one of the categories listed below. This will sometimes result in "compatible" forms and true AACR 2 forms both being used in the new catalogue. In some cases, the two forms can be interfiled; in other cases, Catalogue Maintenance staff will need to correct "compatible" headings in pencil. Acceptable dn forms are:

a. LC will omit hyphens between forenames if the heading has been established without hyphens, even though rule 22.1D2 would require hyphens. Use the LC form, if found. Catalogue Maintenance will interfile headings identical except for the presence or absence of hyphens.

b. LC will continue to place the abbreviation $c a$. after a date in the heading for a person, if the heading has already been established in that form, even though rule 22.18 specifies that the abbreviation should precede the date. Use the LC form, if found. Catalogue Maintenance will interfile headings identical except for the placement of the abbreviation $c a$.

c. LC will not correct the language of an addition to a personal name heading; i.e. will not change to the language used in the person's works. (E.g., a heading already established as Louis Antoine, Father will not be changed to Louis Antoine, père, even though the latter is the author's usage.) Use the LC form, if found. Catalogue Maintenance will correct conflicts in pencil, to the LC form.

d. LC will not change a personal name heading to a fuller form of the name, even if the shorter form is not predominant. Use the LC form, if found. Catalogue Maintenance will correct conflicts created by personal name headings that vary in fullness to the form to which a "see" reference has been made. If there is no "see" reference, Catalogue 
Maintenance will refer the conflict to the appropriate cataloguing service.

e. LC will continue to use additions to surname headings supplied by cataloguers, for headings already established with such additions. Use the LC form, if available. Catalogue Maintenance will resolve conflicts by adding qualifiers in pencil to headings that are otherwise identical with the forms with qualifiers.

f. LC will continue to use titles of honor, address, or nobility with headings that have already been established with such titles, even though the authors do not use such titles. Use the LC form, if found. Catalogue Maintenance will resolve conflicts by adding qualifiers in pencil to headings that are otherwise identical to the forms with the qualifiers.

g. LC will not use initial articles in uniform title and corporate headings, even when they are required by AACR 2 . We will follow LC practice in this, and use the LC form when found. Catalogue Maintenance will interfile uniform title and corporate headings that are identical except for the presence or absence of initial articles.

$\mathrm{h}$. LC will continue to use the abbreviations $\mathrm{Bp}$. and $\mathrm{Abp}$. for personal name headings that have already been established with those abbreviations used as qualifiers, instead of spelling out the qualifiers in full. Use the LC form, if found. Otherwise, follow AACR 2 and spell out "Bishop" and "Archbishop". Catalogue Maintenance will resolve conflicts by correcting in pencil to the form spelled out in full.

i. LC will not add terms of incorporation to corporate headings already established without them, nor delete them from corporate headings already established with them, even though LC interpretation of AACR 2 would require such adjustment. Use the LC form, if available. Otherwise, retain terms of incorporation in corporate name headings only if the term is an integral part of the name, or if, without the term, it would not be apparent that the heading is the name of a corporate body. Catalogue Maintenance will resolve conflicts by adding, in pencil, terms of incorporation to headings identical to established forms except for the absence of such terms.

j. LC will not add geographic qualifiers to corporate headings established previously without such qualifiers, even though they have chosen to apply the option in rule 24.4 that allows qualifiers to be added when there is no conflict. Use the LC form, if available. Catalogue Maintenance will resolve conflicts by adding qualifiers in pencil to headings identical to established headings except for the absence of such qualifiers.

k. LC will not reduce the hierarchy of Far Eastern corporate headings, established before 1981, even though AACR 2 rules would require that intervening superior bodies would be omitted from the heading. Use the LC form, if available. Catalogue Maintenance will refer conflicts to the appropriate cataloguing agency for resolution. The Asian Library Cataloguer is the final authority for such headings.

1. LC will not change the capitalization of acronyms and initialisms to conform to the usage of the corporate body, if the acronym has already been established with a different capitalization. Use the LC form, if available. Catalogue Maintenance will resolve conflicts by interfiling acronyms and initialisms that are identical except for variations in capitalization.

m. LC will not supply quotation marks around elements in a corporate heading that has already been established without quotation marks, even though this varies from the usage of the body. Use the LC form, if available. Catalogue Maintenance will resolve conflicts by interfiling headings identical except for the presence or absence of quotation marks.

n. If LC is attempting to resolve a conflict (i.e. two different people with identical author statements), and neither dates nor expanded initials are available to resolve the conflict, LC will add an unused name in parentheses to the heading if the information is available. E.g.:

established heading: Smith, Elizabeth

new author: Elizabeth Smith 
(New author's full name, Ann Elizabeth Smith, is available)

LC heading: for new author: Smith, Elizabeth (Ann Elizabeth)

Use LC forms if found in name authority file. Catalogue Maintenance will refer problems to the appropriate cataloguing agency.

\section{UNACCEPTABLE dn FORMS}

In a few cases, the AACR 2 "compatible" forms, coded d in authority records and dn in bibliographic records, are unacceptable in the UIUC Library. Instead, we will follow AACR 2 in constructing these headings, and record the LC form on authority cards when they are found. We will also make references from the LC forms, if they would file differently from the forms we use. For many of these, Catalogue Maintenance will have to refer conflicts to the appropriate cataloguing agency. In a few cases, Catalogue Maintenance can make the corrections on the cards. The unacceptable dn forms are:

a. LC will sometimes, but not always, continue to use headings established prior to 1981 with names spelled out in full, when the authors represent some of those names with initials. Follow AACR 2 in constructing headings for these names. Use initials in conformity with the authors' usage, and add the corresponding full names in parentheses, in subfield q, when the information is available. Whenever an element in a compound surname or a first forename is represented by an initial, make a reference from the fuller form. Usually, a reference will not be needed if a forename other than the first is represented by an initial.

b. LC will continue to add "pseud." to personal name headings already established with that qualifier. Do not use the qualifier "pseud." when establishing personal name headings, and delete the term from OCLC records that use it, including records added by LC. Catalogue Maintenance will resolve conflicts by lining out the qualifier "pseud." in headings.

c. LC will continue to add 20 th century fl. dates to personal name headings already established with such dates. Do not use 20 th century fl. dates when establishing personal name headings, and delete such dates from OCLC records that use it, including recorded added by LC. Catalogue Maintenance will resolve conflicts by lining out 20 th century fl. dates in headings.

\section{87x FIELDS}

One part of the AACR 2 conversion project by OCLC was the addition of fields tagged 870 , 871,872 , or 873 . These fields contain the pre-AACR 2 forms of headings that were changed by the conversion. OCLC participants can add $87 \mathrm{x}$ fields to records they enter into the data base. However, we will not supply these fields in our cataloguing.

\section{AUTHORITY CARDS}

Prepare authority cards whenever references are needed, and whenever an LC authority record for the heading is found, even if we do not use the LC form. Citation of the authority record takes the form: "LC Auth. Rec." followed by the record number and the indication, in parentheses, of the code for rules given in subfield w. Example:

Akademie der Wissenschaften und der Literatur (Mainz, Germany)

$$
\text { LC Auth. Rec. } 80076417 \text { (cn) }
$$

If the LC form differs from the form used as the heading in UIUC, give the LC form in parentheses, following the subfield w code. Example:

\section{Abrahamson, Max W. (Max William)}

\section{LC Auth. Rec. 78064817 (dn) (Abrahamson, Max William)}

It will sometimes happen, when establishing the heading for a corporate body, that an LC 
authority record for a subdivision of the body you are establishing will give you the AACR 2 form of the body you are setting up. Precede the citation to the authority record with the word "From". Example:

United States. Environmental Protection Agency. Region V.

From LC Auth. Rec. 80159375 (cn)

(The LC authority record is for the Water Division of Region V)

\section{REFERENCES}

The basic rule for making references is given in AACR 2, rule 26.1: "Whenever the name of a person or corporate body or the title of a work is, or may reasonably be, known under a form that is not the one used as a name heading or uniform title, refer from that form to the one that has been used. Do not make a reference, however, if the reference is so similar to the name heading of uniform title or to another reference as to be unnecessary." Ultimately, this decision depends on the cataloguer's judgement. Usually, make a reference only if it would file differently from the established heading and from all other references. Refer from variant forms found in works catalogued for this library, and in standard reference sources. LC authority records will often suggest useful references. However, we may need references not traced by LC, and we may not need all of the references LC traces. Notice especially that LC authority records will often give a reference from the pre-AACR 2 form, even when it would file with the AACR 2 form. For example, the authority record for Akademie der Wissenschaften und der Literatur (Mainz, Germany) traces a reference from Adakemie der Wissenschaften und der Literatur, Mainz-the pre-AACR 2 form. These two forms would file together, so we do not need the reference.

We will trace "see also" references from forms that can legitimately be used as headings, whether or not they have been used yet in the UIUC library. We will no longer observe the former restriction, which allowed "see also" references to be made only if both headings had been used.

For further information on authority records and references, see the cataloguing manual, section A79.

AW:lgo

Arnold Wajenberg is principal cataloger and Michael Gorman is director, technical services, at the University of Illinois Library. 